\title{
The scale and scope of process $R \& D$ in the Irish pharmaceutical industry
}

\author{
Chris van Egeraat* \\ Department of Geography / National Institute for Regional and Spatial Analysis, National \\ University of Ireland, Maynooth, Ireland
}

\begin{abstract}
Manufacturing Process R\&D activities are one of the target areas of Irish industrial development agencies in their quest towards embedding pharmaceutical companies in Ireland. This paper analyses the changing role of Ireland in the global process R\&D networks of the pharmaceutical companies. The paper is based on data collected in an email survey of all pharmaceutical establishments in Ireland and face-to-face interviews with 13 companies. The article outlines the various stages of the process R\&D cycle and assesses the involvement of the Irish establishments at each stage. Far from a uniform undifferentiated activity, process R\&D comprises a range of activities. The results show that although Irish plants are increasing their involvement in process $R \& D$, this involvement tends to be concentrated in the last stages of the cycle.
\end{abstract}

Keywords: process R\&D; pharmaceutical industry; transnational corporations; Ireland

\section{Introduction}

Since its relatively late introduction at the end of the 1950s, the pharmaceutical sector in Ireland has experienced strong and virtually continuous growth. The implementation of outward-looking economic policies (focused strongly on the stimulation of exports through the attraction of inward investment) from the end of the 1950s (O'Malley 1989) led quickly to the arrival of the first foreign manufacturing plants. Initially the companies in question were primarily attracted by the zero rate of corporation tax on profits derived from exports. The pharmaceutical industry in Ireland really took off in the 1970s after the Industrial Development Authority (IDA) identified the industry as one of its target sectors (Childs 1996, White 2000). Additional attractions for inward investment now included access to the European market (following entry to the European Union in 1973) and an increasingly skilled labour force.

By 2003 the pharmaceutical industry had developed into one of the main industrial sectors in Ireland, employing nearly 19,500 people, over eight per cent of total manufacturing employment (Van Egeraat 2006, Van Egeraat and Barry 2009). Foreign companies account for $93 \%$ of total employment. Employment in the industry more than doubled in the period 1993-2003. Exports of the broader pharmaceutical/chemical industry have grown from about €2 billion in 1990 to €39 billion in 2002 making it the largest export sector in Ireland, accounting for $42 \%$ of

\footnotetext{
*Email: chris.vanegeraat@nuim.ie 
the value of all manufactured goods exported in that year. Since 2001 the sector has been the largest contributor of corporation tax to the Irish exchequer (ICSTI 2003).

Within pharmaceutical manufacturing most employment growth has occurred in the drug formulation subsector, which accounts for about two-thirds of employment, and the higher-value-generating active ingredients sub-sector. There has been very little growth in the (relatively) low-value-generating basic chemicals sub-sector. As regards the underlying technology, the great majority of active ingredient plants produce chemical pharmaceuticals. The biopharmaceutical manufacturing subsector is still small in proportion to the chemical pharma sub-sector, but the relatively recent arrival of a number of large-scale biopharmaceutical fermentation plants suggests that this will become an increasingly important sub-sector in the future (for an analysis of the dynamics in pharmaceutical manufacturing see Van Egeraat and Barry 2009).

For a long time the pharmaceutical industry in Ireland, like most other industries, had a strongly truncated form, involving foreign branch plants focussing on production with little or no R\&D activity. In the context of rising factor costs and the perceived associated threat of plant closures during the second half of the 1990s, Irish industrial policy began prioritising the upgrading and enhanced embedding of firms through, inter alia, encouraging the incorporation of $R \& D$ activities into their operations (Industrial Policy Review Group 1992). Recent policy documents specifically promote process $\mathrm{R} \& \mathrm{D}$ as an important opportunity for higher valueadded activities in the Irish pharmaceuticals industry (ICSTI 2003, Enterprise Strategy Group 2004).

This policy is inspired by a perceived changing spatial configuration of process R\&D activities within the global networks of pharmaceutical firms. Breaking a tradition of concentrating process $R \& D$ activities at the central $R \& D$ sites in the home countries of transnational enterprises, anecdotal evidence suggests that process R\&D activities are increasingly being dispersed to branch plants in the global production networks of these firms (Howells 1984, Chiesa 1996, Pisano 1997). Although many studies address the changing spatial configuration of pharmaceutical product R\&D or pharmaceutical innovation in general (Howells 1983, 1984, 1990, 1995, Cooke 2004, 2005, 2007, Zeller 2004a, 2004b) little detailed work has been done on process $\mathrm{R} \& \mathrm{D}$ and no information exists about the situation in Ireland. The purpose of this article is to investigate the changing concentration and deconcentration forces driving the geography of process $R \& D$ functions in the global pharmaceutical industry and how these changing forces affect the changing profile of the activities of pharmaceutical enterprises operating in Ireland. R\&D may be carried out either inside the transnational firm, in the form of 'internalised R\&D' (Dicken 2003), or through external networks. Process R\&D is still largely organised internally and this article deals exclusively with this internalised R\&D.

The analysis of Ireland's role in process R\&D is based on data collected from two sources: an email survey among all pharmaceutical establishments and multiple faceto-face interviews in 13 selected pharmaceutical companies.

The paper begins with a discussion of existing literature dealing with the geography of R\&D and an account of how the influences of increasing competition and technological change have prompted pharmaceutical companies to restructure the organisation of their process $\mathrm{R} \& \mathrm{D}$ activities. It is postulated that this restructuring is giving rise to the decentralisation of selective process R\&D functions 
to manufacturing sites in relatively peripheral regions, including Ireland. The next section provides a detailed outline of the R\&D cycle in the industry today. Far from a uniform undifferentiated activity, process $R \& D$ consists of a range of activities, potentially involving different tendencies of decentralisation. This provides the necessary background for the following section which contains a detailed discussion of the scale, growth, scope, sophistication and evolution of process R\&D activities in the Irish pharmaceuticals industry. The final section presents conclusions and raises policy issues arising from the findings.

\section{Reorganisation of process $R \& D$ in the pharmaceutical industry - potential spatial implications}

The geography of R\&D in the pharmaceutical industry has long been a popular research topic, particularly for geographers (Howells 1983, 1984, 1990 and 1995; Cooke 2004, 2005 and 2007; Zeller 2004a, 2004b). Much of this work has focussed on the location of product development (discovery) activities, arguably the most value-added element of $R \& D$ in the pharmaceutical industry. Recent studies show how the traditionally high levels of spatial concentration and clustering of product R\&D in the pharmaceutical industry (see below) have increased since the 1980s. A combination of rising costs and the fact that traditional pharmaceutical companies had great difficulty adapting to the shift in the epistemology underlying scientific method from synthetic chemistry to biologics and molecular biology (Cooke 2004) has meant that pharmaceutical companies have become increasingly dependent on external sources of knowledge and a model of open innovation (Chesbrough 2003).

In this new environment universities, research institutions and small dedicated biotechnology firms have become the core sources of knowledge. As a consequence, large pharmaceutical firms are increasingly locating new $R \& D$ facilities in concentrations of such knowledge in an attempt to tap into these sources and avail of the concomitant pool of talent. Thus, although large pharmaceutical companies undertake a greater proportion of their R\&D outside their home countries, much of this internationalisation has been spatially highly selective, tending to concentrate in a small number of 'innovation arenas' (Zeller 2004a) or 'megacentres' such as Boston, San Francisco, San Diego, Cambridge and Munich (Cooke 2004).

Although R\&D in the pharmaceutical industry is characterised by increasing levels of spatial concentration, elements of $R \& D$ may be characterised by different spatial dynamics. Rather than a uniform activity, pharmaceutical R\&D includes a range of separate activities. The literature tends to focus on product $R \& D$, while little detailed work is done on process $\mathrm{R} \& \mathrm{D}$. However there are reasons to believe that process $R \& D$ is characterised by a different spatial dynamic. To understand this it is helpful to discuss process R\&D in the context of the shift from a Fordist to a post-Fordist mode of production (Amin 1994).

Until about the 1980s, the international pharmaceutical industry developed under Fordist principles. R\&D had developed as a linear process (Malecki 1997, Hayter 1998, Dicken 2007) involving a continuum of activities leading from basic research through applied research and product/process development to technology transfer to the commercial manufacturing plants. Within large corporations, ideas were progressively researched, developed and transferred to the production plants. 
Functions were highly specialised and compartmentalised (Zeller 2004a, 2004b). There was a strong distinction between the individual R\&D functions and between the $R \& D$ and manufacturing functions. Each $R \& D$ group constituted its own compartmentalised speciality responsible for a particular task in the linear process. Planned interactions between departments were constrained to the moments of transfer of a finished task.

The Fordist method of work organisation was associated with a distinct geography of production and $\mathrm{R} \& \mathrm{D}$. The geography of production was characterised by a decentralisation of manufacturing functions. In the post-war period many pharmaceutical companies rapidly expanded their manufacturing networks both inside their home countries and abroad. Companies established branch plants in numerous markets to overcome trade-barriers and, in countries such as Ireland and Puerto Rico, to avail of local tax incentives. These foreign-owned branch plants were typically involved in the commercial-scale manufacture of end-of-life-cycle products and characterised by a generally low level of embeddedness in the local economy (Britton and Gilmour 1978, Watts 1981, Collins and Grimes 2008).

The Fordist geography of R\&D was different from that of production. The R\&D functions of transnational companies, particularly the basic research functions of transnational pharmaceutical companies remained firmly located in the home countries, in the central research units located near the head-offices and main production sites of the companies (Cooke 2005). Concentrating R\&D staff was believed to bring efficiency and productivity gains. Branch plants frequently housed small technical and development units, but the scope of the activities was limited (Howells 1984, Hayter 1998). Even in the case of process R\&D, typically, the manufacturing process was for the most part developed by the central R\&D group located near the head-office before the technology was transferred to the manufacturing function and manufacturing sites.

The Fordist approach to R\&D involved inherent inefficiencies. The linear approach and highly specialised and compartmentalised organisation of functions are unsuitable for the realities of research projects where decisions taken during the early stages of the cycle strongly influence the possibilities and parameters for the later stages, and vice versa. The lack of integration and communication between the various R\&D functions and between the R\&D and manufacturing plants led to a lot of wastage, high costs and long development times (Hayter 1998, Zeller 2004a and $2004 b$ ). In pharmaceutical process $R \& D$, because of the late involvement of the manufacturing function, problems and inefficiencies in the manufacturing process were identified at a very late stage in the process $R \& D$ cycle. This tended to delay the product launch and/or led to significant post-launch changes to the process that involved time-consuming regulatory re-filing procedures.

These inherent deficiencies in the Fordist innovation model became increasingly problematic during the 1980s when, confronted with important global changes in the competitive and technological environment, pharmaceutical companies came under pressure to increase efficiency in product and process R\&D (Zeller 2004a and 2004b). This typically involved a shift towards an R\&D organisation that explicitly incorporated the 'loopy' nature of the R\&D process (Hayter 1998). The traditional compartmentalised structures were increasingly replaced by cross-functional product/process development teams that embraced the different R\&D functions as well as non-R\&D functions such as manufacturing and sales and marketing (Zeller 
2004a). As regards process $R \& D$, in many cases companies sought the solution in earlier involvement of the manufacturing function in the process R\&D cycle (Pisano 1997, Van Egeraat 2007).

The post-Fordist drive towards a greater integration of process $\mathrm{R} \& \mathrm{D}$ with, on the one hand, product $\mathrm{R} \& \mathrm{D}$ functions and, on the other hand, manufacturing functions raises interesting questions regarding the relative strength of spatial concentration and deconcentration forces in determining the geography of process $R \& D$. As discussed, the traditionally high level of spatial concentration and clustering of product R\&D in the pharmaceutical industry has further increased since the 1980s and the majority of product $\mathrm{R} \& \mathrm{D}$ laboratories are concentrated in the core regions of a small number of core countries (see also Dicken 2007). On the other hand, pharmaceutical companies are operating relatively decentralised production networks with manufacturing plants located in many countries, including in relatively peripheral economies such as Ireland and Puerto Rico, and they continue to do so in relation to biopharmaceutical plants (Cooke 2004, Van Egeraat and Barry 2009). Is the drive towards organisational integration and communication between process $\mathrm{R} \& \mathrm{D}$ and manufacturing addressed by a decentralisation of process $\mathrm{R} \& \mathrm{D}$ functions to manufacturing sites in these peripheral locations? The postulation in this article is that this is the case but that it affects only a select set of process R\&D activities.

In the conventional classification, process $R \& D$ is typically treated as a uniform category. Process R\&D in the pharmaceutical industry is far from being a uniform, undifferentiated, function. Instead, it comprises a wide range of activities, some of which cross the boundary with applied research. The individual activities may involve different tendencies of decentralisation. This article examines the extent to which the trend of decentralisation of process R\&D activities in the global networks of transnational pharmaceutical companies is affecting Ireland. The next section begins by providing a detailed outline of the R\&D cycle in the industry today.

\section{The $R \& D$ cycle of the pharmaceutical industry}

Conventional classifications typically treat process R\&D as a uniform category. This section aims to open the 'black-box' of process R\&D activities in pharmaceutical companies. For a more detailed description of the pharmaceutical R\&D cycle, see Van Egeraat (2007). The R\&D cycle entails two largely parallel but quite distinct sets of activities i.e. 'product' and 'process' R\&D. The pharmaceutical R\&D cycle includes both the development of new 'active ingredients'-also referred to as drug substances-and the development of related finished drug 'formulations' (the actual tablet, capsule, injection, spray or patch through which the active ingredient is delivered to patients). Pharmaceutical products can be derived through both chemical synthesis and biotechnological processes. While the development of the two types of drugs involves quite different activities, in both cases the same broad stages can be identified.

The product R\&D cycle can be divided into four stages: initial drug discovery, pre-clinical development, clinical development and regulatory approval (see Figure 1) (see Pisano 1997). The discovery stage is concerned with research into the causes of diseases and the identification of compounds that could be active in relation to the treatment of certain diseases. Compounds that offer most potential (drug candidates) are then tested on animals in the pre-clinical development stage, with any candidate 


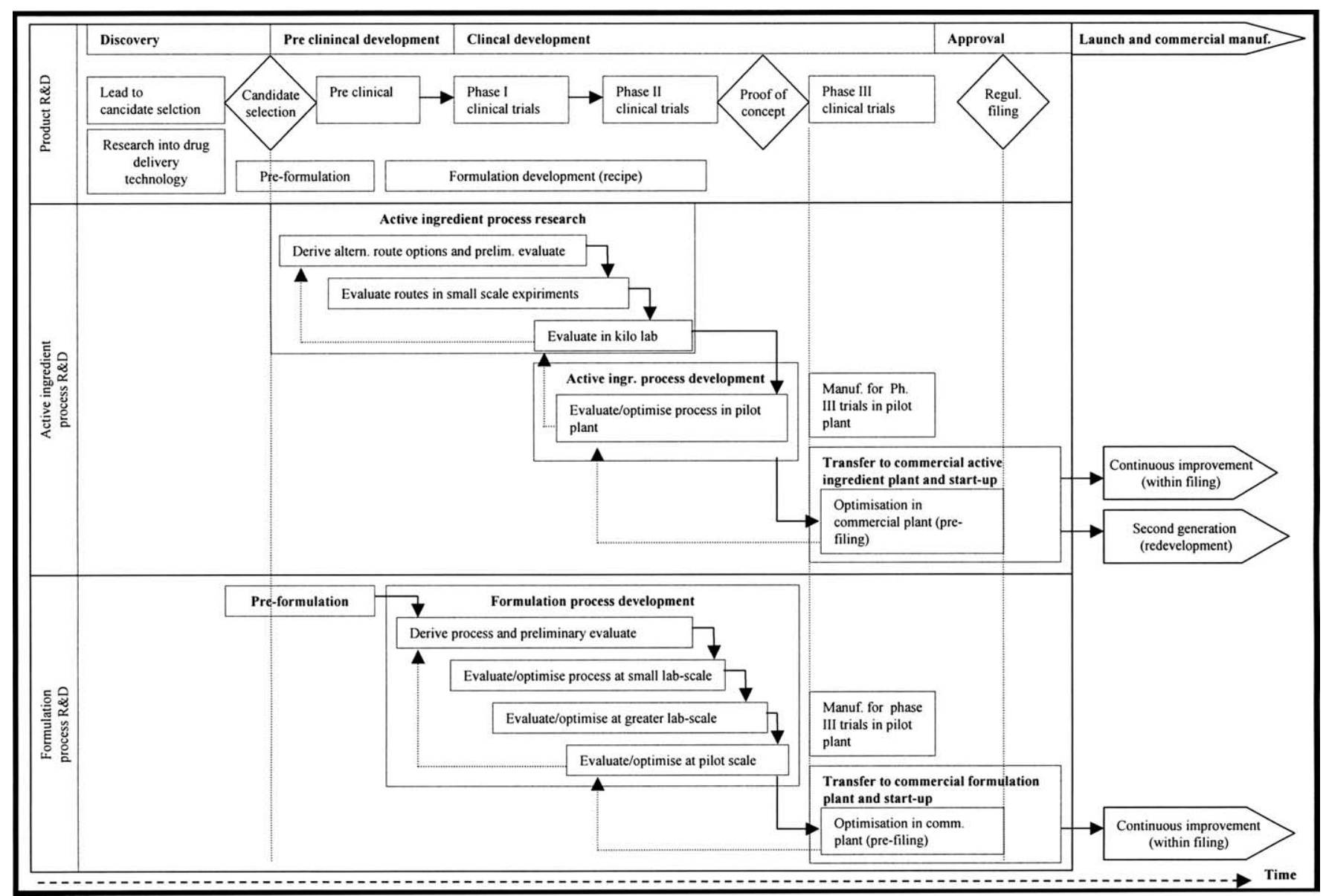

Figure 1. Process R\&D cycle for chemically synthesised drugs. 
that emerges successfully from this stage entering the clinical development stage, during which the drug is tested on humans. This stage generally involves three phases, during which the drug is tested on increasingly large groups of human subjects. Successful Phase II trials can lead to the drug candidate achieving what is termed 'proof of concept' status which sanctions the commencement of the costly Phase III trials, where the drug is tested on thousands of patients.

In parallel with drug product $\mathrm{R} \& \mathrm{D}$, and strongly integrated with it, runs drug process $\mathrm{R} \& \mathrm{D}$. The tasks of process $\mathrm{R} \& \mathrm{D}$ are to develop an effective process for the large scale manufacturing a new drug product and to supply material for the clinical trial stages of the product $\mathrm{R} \& \mathrm{D}$ cycle (while the clinical trials are part of the product development, the actual manufacturing of the clinical batches is the responsibility of the process development function). Process R\&D involves two separate but integrated cycles, one for the active ingredient and one for the drug formulation. The process $\mathrm{R} \& \mathrm{D}$ cycle for active ingredients involves a number of integrated activities or stages. The cycle usually starts immediately after candidate selection with pre-formulation studies. Companies develop a deeper understanding of the candidate drug and explore alternative synthetic routes or processes. Promising routes or processes are then progressively evaluated and scaled up via 'paper experiments', computer simulation, small-scale laboratory experiments and experiments in the 'kilo lab' (a larger laboratory scale). Subsequently the activities move to the pilot plant where the process is further scaled up (typically to $10 \%$ of commercial scale), with the research focus now on optimising flow rates and equipment design and developing process mechanics. Apart from developing a manufacturing process, a second important function of the pilot plant is to produce material for larger-scale (Phase II and Phase III) clinical trials.

The process $R \& D$ cycle concludes with the transfer of drug production to commercial-scale plants which involves final equipment design, optimisation in the commercial plant, validation, documentation of standard operating procedures and the training of operating staff. Process development continues during the entire life cycle of a drug in the form of continuous improvement activities conducted by technical staff at the commercial plant. This typically involves small, incremental, changes that do not require re-filing with the regulatory authorities. In addition, many companies will now start a new cycle of process R\&D for the same compound, generally referred to as 'second generation'. Such redevelopment activities, although requiring re-filing, tend not to involve a fundamental route change.

In parallel, the company needs to develop a manufacturing process for the drug formulation. The manufacturing process of a drug formulation differs strongly from that of an active ingredient. In the chemical synthesis of an active ingredient, raw materials are transformed through chemical reaction into a final compound - a chemical transformation. In drug formulation manufacturing the active ingredient is combined with other, inactive ingredients in a physical transformation process. This is arguably a less complex process but can nevertheless involve a substantial development effort. The stages in process R\&D of the drug formulation are similar to those in active ingredient process $R \& D$. After pre-formulation studies the 'formulation process development' group identifies a potential manufacturing process which is then evaluated and scaled up from a small laboratory scale to an 
intermediate laboratory scale and finally to a pilot scale in the pilot plant, akin to the process $\mathrm{R} \& \mathrm{D}$ cycle of an active ingredient. As in the active ingredient process $\mathrm{R} \& \mathrm{D}$ cycle, an important function of the drug formulation pilot plant is to produce material for Phase III clinical trials. Very much along the lines of the active ingredient process $R \& D$ cycle, the manufacturing process $R \& D$ cycle for the drug formulation ends with the transfer to the commercial manufacturing plant, validation and regulatory filing, although continuous improvement will continue throughout the life cycle.

The above subsections present a stylised picture of the process $R \& D$ cycle. In reality the process $\mathrm{R} \& \mathrm{D}$ cycles can differ from product to product. Depending on the technology involved, the scale of the eventual process and the requirements for regulatory approval, the cycle may not include all of the described stages. For example, in the case of niche products that require relatively small quantities of product, one of the scale-up steps may be omitted.

The various stages in the process $R \& D$ cycle require different numbers of researchers with different skill sets. Although all stages can involve skilled and highly educated staff, the early stages in the cycle involve the greatest number of, and the most highly skilled, researchers. Companies generally aim to have most major decisions regarding the essential production process ('lock down' the process) made in advance of the large-scale testing involved in Phase III clinical trials. From here on, process development focuses on the final details of the process.

The various stages of the process $\mathrm{R} \& \mathrm{D}$ cycle are strongly dependent on each other and on other functions in the pharmaceutical value chain. The activities during the initial stages of the process $\mathrm{R} \& \mathrm{D}$ cycle, also referred to as process research, are strongly integrated with each other as well as the discovery function in the product R\&D cycle. The pilot plant functions have links with the process research, the manufacturing functions as well as the clinical trials function in the product R\&D cycle. The subsequent activities tend to have strong links with manufacturing. Given the different global spatial configurations of discovery and manufacturing functions it is likely that individual stages of the process $R \& D$ cycle will have different tendencies of decentralisation. The next section provides an account of how the decentralisation of process $R \& D$ activities is affecting Ireland

\section{Process R\&D activities in pharmaceutical firms in Ireland}

\section{Data sources}

The analysis of Ireland's role in process $R \& D$ which follows is based on data collected from two sources: multiple interviews at 11 transnational pharmaceutical companies and an email survey of all pharmaceutical companies in Ireland. Semistructured, face-to-face, interviews were conducted with senior staff at major pharmaceutical plants in the period 2005-2006. A total of 53 staff members were interviewed, including general managers, materials managers, personnel managers and process development managers. The material presented in this paper is based mainly on information obtained during the interviews with the process development managers. In one case interviews were conducted with global process development managers located at global head-quarters. These interviews were used, inter alia, to obtain detailed micro-level data about the dynamics of the global organisation and 
spatial configuration of process $\mathrm{R} \& \mathrm{D}$ activities in the pharmaceutical companies, with particular reference to the relative role played by the Irish subsidiaries in these activities. The selection process ensured that the sample included companies in different sub-sectors (drug product and drug formulation), from different nationalities (US, UK, Swiss, French and Japanese), with different levels of involvement in process R\&D and with different locations in Ireland.

In addition, an email survey was conducted of all pharmaceutical establishments in Ireland in the period 2006-2007. A list of pharmaceutical companies was obtained from the annual Employment Survey of manufacturing operations in Ireland, conducted by Forfás (the National Policy Advisory Board for Enterprise, Trade, Science, Technology and Innovation). This list was thoroughly checked and amended on the basis of information obtained through Internet-based research combined with short telephone interviews. Establishments with only a marketing or distribution function were excluded. In addition, a small number of establishments were excluded because they were still in the construction phase. The final list included 80 establishments. For a more detailed report of definitional and recoding issues see Van Egeraat (2006).

Process development managers or managers of technical services were personally approached and asked to complete a two-page questionnaire. Following an intensive survey administration process, 76 useable questionnaires were returned - a response rate of $95 \%$. The Forfás Employment Survey shows that the 76 respondent companies represent $92 \%$ of all employees employed by the listed pharmaceutical companies. The survey therefore covers nearly the entire pharmaceutical industry. Table 1 presents the characteristics of the sample of 76 respondent companies. About a third of the establishments were exclusively involved in the production of active ingredients, $58 \%$ in drug formulation and the remaining $8 \%$ manufactured both active ingredients and drug formulations.

The questionnaire sought information on, inter alia, the age of the establishment, the product, the number of employees involved in process $R \& D$ and their education level, and the role of the local units in the global process R\&D networks of the companies. With regard to the latter, it was recognised that the post-Fordist organisation of process $R \& D$ tends to involve global project teams made up of staff of different R\&D functions as well as manufacturing and marketing. In such structures, local units tend to have at least some input in most process R\&D activities and it is often not possible to characterise the location of the various activities in terms of 'here or there'. To get an insight into the relative role of the local units in the

Table 1. Characteristics of the 76 respondent companies.

\begin{tabular}{lrrc}
\hline & Sample & $\begin{array}{c}\text { Population } \\
(\mathrm{N}-80)\end{array}$ & $\begin{array}{c}\text { \%-age of } \\
\text { population }\end{array}$ \\
\hline Number of companies & 76 & 80 & 95 \\
Employees & 18,554 & 20,195 & 92 \\
Active ingredients & 26 & & \\
Drug formulation & 44 & & \\
Both active ingredients and & 6 & & \\
drug formulations & & & \\
\hline
\end{tabular}

\footnotetext{
*Employment numbers and percentages based on Forfás employment survey data, 2006.
} 
overall network, in this research respondents were asked to rate the relative input of the local staff in various process $R \& D$ activities on a seven-point Likert scale $(1=$ no input; $7=$ sole ownership). The same questionnaires were used for drug substance and drug product plants. For reasons of clarity, the questionnaire sent to the biopharmaceutical active ingredients (fermentation) plants used a slightly different terminology but included the same broad stages.

Follow-up phone calls to some of the respondent firms were made in order to clarify answers and obtain supplementary information. These phone calls often provided valuable qualitative information on process $R \& D$ activities that informed the analysis.

The results of the company interviews and an email survey are used in a complementary way to analyse the process R\&D activities in the Irish pharmaceutical industry. The quantitative data from the email survey are used to construct a broad overview of process R\&D in the Irish pharmaceutical industry and the relative role of Irish establishments in the various process $R \& D$ activities. The interview data serve to obtain a more detailed and nuanced understanding of the relative role of Irish establishments, notably the changing nature of this role.

\section{The scale of process $R \& D$ in Ireland}

The survey of pharmaceutical firms in Ireland shows that, at the end of 2006, the 76 respondent companies employed a total of 800 staff involved in process R\&D, irrespective of the proportion of their time spent on these activities. These people were either part of dedicated process R\&D units or were employed in other functions such as production, technical support, quality control, etc. Most people spent only part of their time on process $R \& D$ activities. Respondents were asked to estimate the proportion of their time that the people involved spent on process R\&D activities. Based on this information it is estimated that process $R \& D$ employed the equivalent of 580 full-time people.

The average number of people involved in process R\&D per firm was 10.5 but the distribution is strongly skewed (see Figure 2). More than $40 \%$ of the companies had less than 5 staff involved in process R\&D while in two-thirds of the companies less

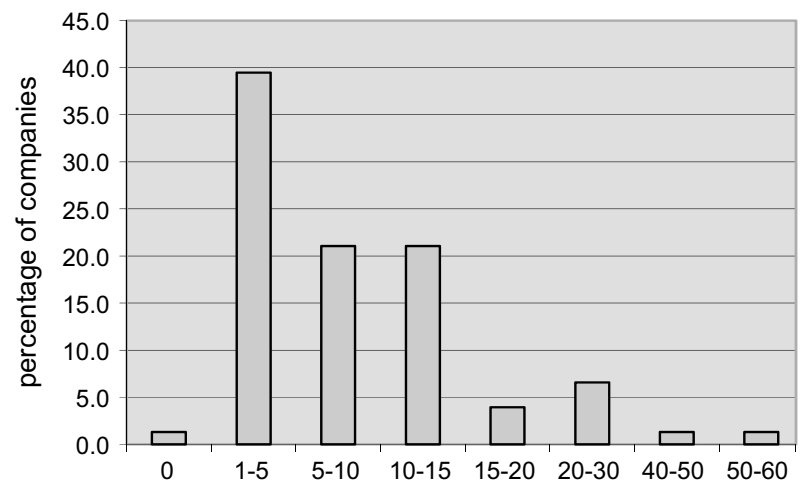

Figure 2. Number of persons employed in process $R \& D$ (percentage of companies in size category). 
than 10 people were involved. Four companies had over 50 people involved. In one case the high figure was related to the fact that the establishment was still partly in the ramp-up phase. A large part of the staff was therefore involved in process R\&D activities as defined in this research but the majority would have subsequently been transferred into manufacturing after the start-up phase.

The survey confirms the rapid recent expansion of process R\&D activities in Ireland. In the six-year period between 2000 and the end of 2006, the number of people involved in process $\mathrm{R} \& \mathrm{D}$ in the responding companies nearly doubled, from 408 to 800 . To put this growth in perspective, total employment in the 76 respondent companies grew by $36 \%$ over the same period. On average the plants that existed in 2000 had an additional three staff involved in process R\&D in 2006. Figure 3 shows that $22 \%$ of these plants experienced no change in the number of persons involved, while eight per cent increased their process R\&D staff numbers by more than 10 people. Six per cent of the incumbent operations experienced a reduction in process R\&D staff. By 2006, the twelve operations that entered the sector since 2000 employed an average of 17 people involved in process R\&D activities. Apart from the fact that some of these companies engaged a greater number of staff in process R\&D during the ramp-up phase, this greater growth in employment of process R\&D staff is partly explained by the relative size of some of the new operations in question.

As for the future, $38 \%$ of the respondent companies had concrete plans to expand their process $R \& D$ activities in Ireland over the next five years. Out of the 31 companies with concrete expansion plans, 27 provided an estimate of the additional process $\mathrm{R} \& \mathrm{D}$ staff requirements over this period, amounting to a total of 311 additional staff. The total increase in the sector will most likely be far greater than this since the question only referred to concrete plans. Almost half of the 311 staff are accounted for by just three companies which were planning major expansions. Staff numbers involved in the other planned expansions ranged from one to 20 .

\section{The scope of process $R \& D$ in Ireland}

Although impressive in their own right, the above figures tell us little about Ireland's relative role in the global process $\mathrm{R} \& \mathrm{D}$ networks of the respondent firms. To get an insight into this role, respondents were asked to rate the relative input of the local

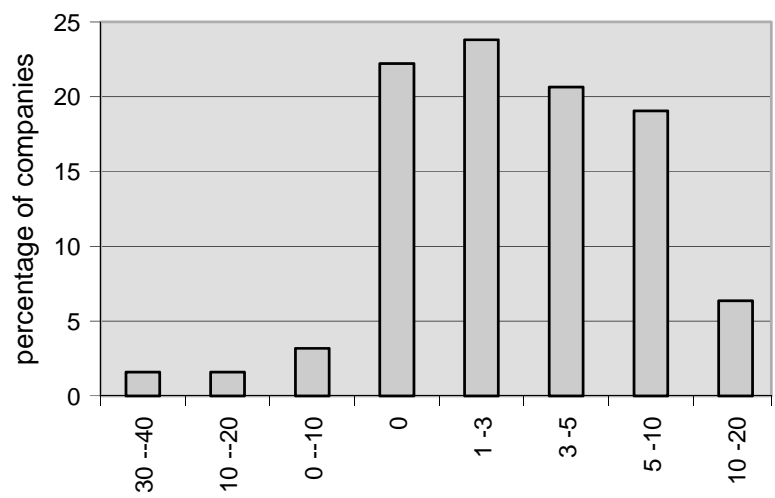

Figure 3. Growth in process development staff 2000-2006 (incumbent companies). 
staff in various process $R \& D$ activities on a seven-point Likert scale $(1=$ no input; $7=$ sole ownership). This section first discusses the results of the drug substance and drug products sub-sectors combined, followed by a discussion of the differences between the sub-sectors.

Most indigenous companies and a small number of foreign-owned companies were single-site operations. In these cases the question regarding the relative input of local staff is not relevant since the local establishments had full ownership of all activities that were relevant to the companies in question. Because of this, the following discussion only pertains to the 63 multi-site companies (i.e. companies with manufacturing or research operations in more than one country) in the survey. Not all research categories were relevant to all companies. For example, some companies producing over-the-counter and generic pharmaceuticals did not have to go through elaborate Phase I and Phase II clinical trials. Therefore the results for the various research activities pertain to different numbers of companies (ranging from 58 to 62).

Table 2 and Figure 4 present the average scores accorded by the respondents to the various research activities. The column with the title ' 1 ' states the percentage of relevant companies that accorded a score of 1 to their involvement in a particular research category, and so forth. The final column lists the mean scores for involvement of the local companies in the various research categories. The results show that the Irish companies tend to have very little involvement in the early stages of the process $\mathrm{R} \& \mathrm{D}$ cycle. The mean score for involvement in 'pre-formulation studies' (2.0) indicates a very low level of involvement. Three-quarters of the establishments for which this activity was relevant had no input in it while only $5 \%$ had sole ownership. The mean score for 'deriving initial route/process options and preliminary evaluation through paper experiments' was even lower (1.9). Here again, a large proportion of the relevant establishments had no input whatsoever while only $5 \%$ had sole ownership. The mean scores for 'evaluation in small-scale experiments' and 'evaluation in kilo lab' were only marginally higher and the percentage of establishments having full ownership remained below $10 \%$.

The interviews confirmed that local technology staff were generally involved in process $\mathrm{R} \& \mathrm{D}$ as members of global project teams made up of staff from R\&D and the manufacturing organisations from various locations. Such teams are set up an early stage of the process $R \& D$ cycle to facilitate an early involvement of all the relevant functions, including manufacturing, and to streamline the transition between the various stages and locations.

The involvement of the Irish establishments rose at the Phase II clinical trials stage. The mean score for involvement in 'production for Phase II clinical trials' was 2.6 while the mean score for involvement in 'evaluation and optimisation of the process' at this stage was 2.7. However the mean scores conceal significant differences between the Irish involvement in the two activities. Of the establishments for which production for Phase II clinical trials was a relevant category, only 47 per cent had at least some input (scoring 2 to 7 ) in this activity. Sixty per cent of the same group of establishments had at least some input in the evaluation of the process at this stage. Although a greater proportion of companies had some involvement in evaluation/optimisation, this involvement tended to be very limited, with over onethird of the respondents scoring either two or three. At the other end of the scale, a substantially larger proportion of establishments in the same group had full 
Table 2. Involvement of local staff in process R\&D activities.

\begin{tabular}{|c|c|c|c|c|c|c|c|c|c|}
\hline & 1 & 2 & 3 & 4 & 5 & 6 & 7 & & mean \\
\hline Pre-formulation studies. & 74.6 & 6.8 & 0.0 & 1.7 & 5.1 & 3.4 & 8.5 & 100 & 2.0 \\
\hline $\begin{array}{l}\text { Derive initial route/process options and } \\
\text { preliminary evaluation }\end{array}$ & 71.0 & 11.3 & 1.6 & 3.2 & 6.5 & 1.6 & 4.8 & 100 & 1.9 \\
\hline Evaluate in small scale experiments & 63.9 & 13.1 & 3.3 & 3.3 & 4.9 & 1.6 & 9.8 & 100 & 2.2 \\
\hline Evaluate in kilo lab & 62.1 & 10.3 & 5.2 & 1.7 & 5.2 & 6.9 & 8.6 & 100 & 2.3 \\
\hline Production for Phase II clinical trials & 52.8 & 13.2 & 5.7 & 5.7 & 7.5 & 1.9 & 13.2 & 100 & 2.6 \\
\hline $\begin{array}{l}\text { Evaluate and optimise process in pilot plant } \\
\text { prior to Phase III clinical trials }\end{array}$ & 39.6 & 17.0 & 17.0 & 7.5 & 5.7 & 5.7 & 7.5 & 100 & 2.7 \\
\hline Production for Phase III clinical trials & 25.9 & 5.6 & 9.3 & 9.3 & 14.8 & 16.7 & 18.5 & 100 & 4.1 \\
\hline $\begin{array}{l}\text { Evaluate and optimise process in pilot plant } \\
\text { during Phase III clinical trials }\end{array}$ & 27.8 & 9.3 & 14.8 & 7.4 & 16.7 & 13.0 & 11.1 & 100 & 3.6 \\
\hline Equipment design & 9.7 & 9.7 & 11.3 & 14.5 & 19.4 & 19.4 & 16.1 & 100 & 4.5 \\
\hline Optimisation in commercial plant (pre filing) & 4.8 & 3.2 & 3.2 & 6.5 & 16.1 & 21.0 & 45.2 & 100 & 5.7 \\
\hline Validation & 0.0 & 0.0 & 3.2 & 4.8 & 6.5 & 22.6 & 62.9 & 100 & 6.4 \\
\hline Continuous improvement & 0.0 & 1.6 & 0.0 & 1.6 & 9.7 & 21.0 & 66.1 & 100 & 6.5 \\
\hline $\begin{array}{l}\text { Development of second generation process } \\
\text { (outside filing parameters) }\end{array}$ & 9.8 & 8.2 & 14.8 & 4.9 & 14.8 & 11.5 & 36.1 & 100 & 4.9 \\
\hline
\end{tabular}

Note: scores on a 7 -point Likert scale $(1=$ no input; $7=$ sole ownership) 


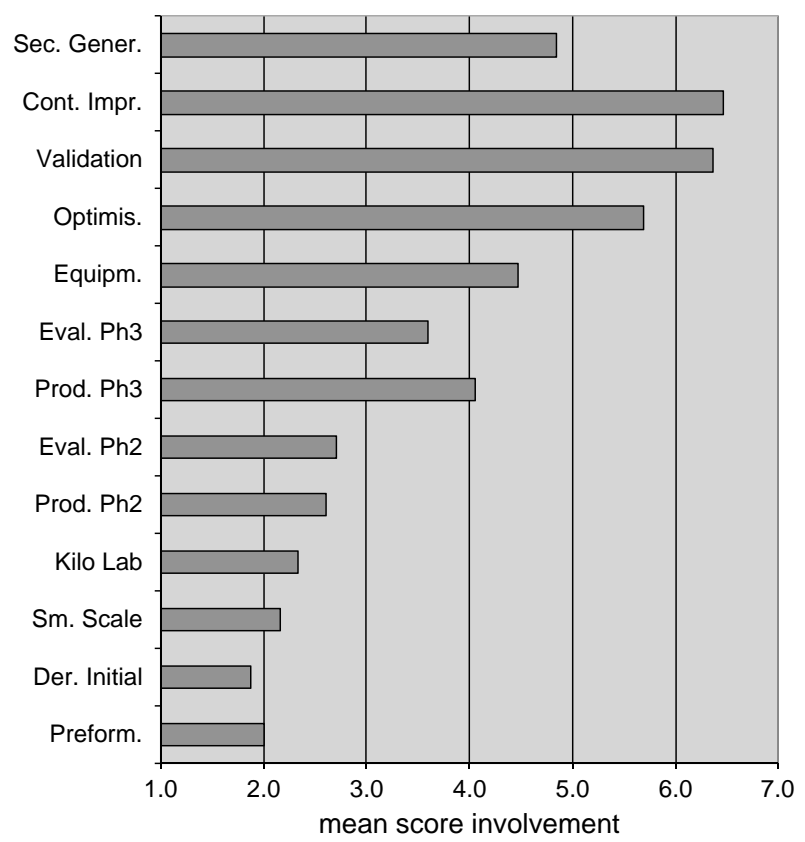

Figure 4. Involvement of Irish subsidiaries in process R\&D activities.

Notes: a Average scores on a seven-point Likert scale $(1=$ no involvement; $7=$ sole ownership); b For full names of categories see text.

ownership of production for Phase II clinical trials (13.2\%) than of the evaluation/ optimisation of the process $(7.5 \%)$.

The pattern is even more pronounced in the context of Phase III clinical trials. The involvement of the local establishments at this stage was substantially greater, with a mean score of 4.1 for 'production' and 3.6 for 'evaluation/optimisation'. Again the proportion of relevant establishments with no input in 'production' was somewhat smaller than the proportion that had no input in the 'evaluation/ optimisation'. At the same time, $35 \%$ of the relevant companies rated their involvement in production of Phase III batches at a score of six or seven compared with only $24 \%$ in relation to evaluation/optimisation activities.

This pattern reflects the fact that the staff involved in process R\&D in Irish pilot plants and commercial plants are focussing on the production aspect of process R\&D activities. As shown in Section 3, apart from developing the manufacturing process, a second important function of pilot plants is to produce material for largescale clinical trials. The survey data suggest, and the interviews confirm, that in a substantial number of cases the main function of the staff involved in process development was the manufacture of material to support clinical trials. A large part of the evaluation/optimisation is carried out by staff from the process R\&D groups in the core global research locations, both at these core locations and/or at the site in Ireland.

In many cases, staff from the Irish units, as members of the global project teams, have some involvement in evaluation/optimisation, even if they are not involved in the production of the evaluation batches. In some cases local staff have a strong 
input in the evaluation of the batches and subsequent optimisation of the process. However, more often the involvement is very limited, particularly at the early stages. One respondent who gave a rating of three to his establishment's involvement in evaluation/optimisation during Phase III clinical trials commented: 'We do produce for clinical trials but the scope of our activities is clearly defined by the guys in the US and therefore our involvement in optimisation is limited as well. But we acquire in-depth knowledge and are involved in discussions'.

The mean score for involvement in equipment design was 4.5. Despite the fact that more than half the companies scored 5 or higher, a substantial group of companies $(31 \%)$ had either a rather limited involvement in this activity or none at all. As expected, the involvement of the Irish establishments tends to rise significantly at the stage of 'optimisation in the commercial plant (pre-filing)'. This optimisation is part of the broader technology transfer phase. Technology transfer essentially involves taking a process from the pilot plant scale and replicating it with, preferably, minor changes (optimisation) at the commercial manufacturing plant. This activity is typically organised through commissioning teams that include staff from the transferring location and, on the receiving end, local staff with responsibility for new product introductions.

The data indicate that local staff have a high level of involvement in the actual optimisation activities (mean score of 5.7). In $45 \%$ of the cases local staff had full ownership while $37 \%$ of the respondents indicated a high level of involvement (scoring a 5 or a 6). These figures pertain to situations where no major process changes are necessary. Significant changes require a strong involvement of the transferring location but such changes tend to be avoided at this stage. Instead companies prefer to divert the making of major changes to the development of second generation processes. Local staff tend to have even greater involvement in the running of 'validation' batches, with $63 \%$ of the respondents indicating full ownership.

'Continuous improvement activities after filing' tend to be carried out almost entirely by the local staff. The mean score for this activity is 6.5 with two-thirds of the respondents stating they had full ownership. At this stage staff from the core research locations tend to have a very limited, more consultative, role. In many cases there is not even a requirement to formally communicate improvements to the central research locations. However, information on process improvements continues to be shared and discussed with the central research locations and other functional units through the global project teams and technology networks.

Finally, the mean score for the level of involvement drops to 4.9 with respect to the 'development of second generation processes (outside filing)'. Some 36\% of the respondents stated that they had total ownership of this activity. It is important to appreciate that this category does not involve a single activity but can involve all of the previous ones. In addition, the development of second-generation processes entails very different activities from company to company. In many companies it involves relatively minor changes, requiring limited technological resources, while in other companies it involves the development of an entirely different chemical route, basically repeating the process $R \& D$ cycle. Many of the companies which stated that they had total ownership of the development of the second generation process were likely to be part of the first group. At the same time, the substantial number of companies giving evidence of more limited involvement included companies from the 
second group. One establishment that included a global dedicated second-generation process development group reported how, even in this case, a substantial part of the activities was carried out by staff of the central research groups:

Basically, the way it actually works is that we are responsible for finding the secondgeneration products. We would identify where the needs are, because we work for manufacturing and then we find out what the solution is and we don't care where the solution is. [...] It could be a research unit in [head-quarters], or it could be ourselves. It depends on the complexity. [...] We have done some [second generation process R\&D] (Manager global process development unit, AI plant, firm 5, 2006).

Overall the data clearly show that the involvement of the Irish staff in process R\&D only becomes substantial after the proof-of-concept point, at the start of Phase III clinical trials. As pointed out in the outline of the process R\&D cycles, this is the point at which companies generally want to have the process parameters locked down. From here on process R\&D activities focus on the final details of the process and technology transfer.

Figure 5 breaks down the data between drug substance and drug formulation establishments. Five multi-location companies which produced both substances and formulations were excluded from the analysis. The data suggest that there is no

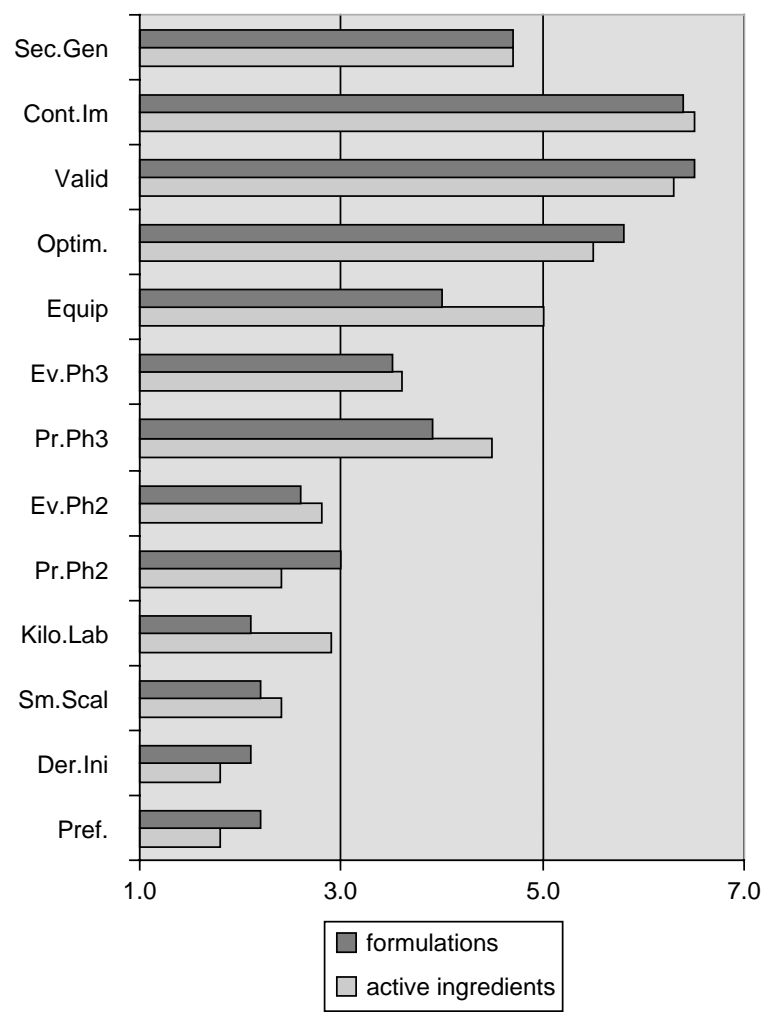

Figure 5. Involvement of Irish subsidiaries in process R\&D activities by sub-sector. Notes:

a Average scores on a seven-point Likert scale $(1=$ no involvement; $7=$ sole ownership $)$

b For full names of categories see text. 
strong link between sub-sector and level of involvement. For most categories, the differences in the average level of involvement of the two groups of establishments were relatively small. The largest differences occur in the areas of 'equipment design' ( 0.9 points) and 'evaluation of route/process options in the kilo lab' (0.8 points), with drug substance establishments scoring higher in both cases. However, there is no obvious pattern in the differences, with the drug substance companies having a greater involvement in eight of the categories and drug formulation companies having a greater involvement in five.

\section{The sophistication of process $R \& D$ activities in Ireland}

The education profile of staff involved in process $R \& D$ can be used as an indicator of the quality or sophistication of the process $R \& D$ activities being carried out in Ireland. The survey shows that the process $R \& D$ activities in the Irish pharmaceutical industry employ a substantial number of highly skilled people. Overall, $30 \%$ of the 800 people involved held a $\mathrm{PhD}$ as their highest level of academic attainment, $19 \%$ held a Masters degree, while a further $46 \%$ held a third-level degree.

The number of PhDs varied considerably between companies. One-third of the companies did not employ a single $\mathrm{PhD}$ in process $\mathrm{R} \& \mathrm{D}$ while another third employed more then $3 \mathrm{PhDs}$, including one company which employed 40. The number of PhDs employed is partly a reflection of the size of the overall operations. But even when we control for overall establishment size, the numbers vary substantially. Figure 6 presents the numbers of $\mathrm{PhDs}$ as a percentage of all staff employed per establishment in 2006. In the great majority of cases the number of PhDs in process R\&D accounted for less then $3 \%$ of all staff. In $11 \%$ of the companies PhDs accounted for between 5 and $10 \%$ of staff while in two companies they made up as much as $13 \%$ of staff.

The number of PhDs involved in process $\mathrm{R} \& \mathrm{D}$ varied strongly by sub-sector, with drug formulation plants tending to employ fewer numbers than active ingredient plants. Figure 7 shows that half of the drug formulation plants did not employ a single $\mathrm{PhD}$ in process $\mathrm{R} \& \mathrm{D}$, compared to only $4 \%$ of the active ingredient plants. At the other end of the scale, two-thirds of the active ingredient plants employed 3 or more PhDs in process R\&D compared to only $14 \%$ of the drug formulation plants. Thus, although the previous section showed that the two sub-sectors tend to be involved in the same, final, stages of the process R\&D cycle, in

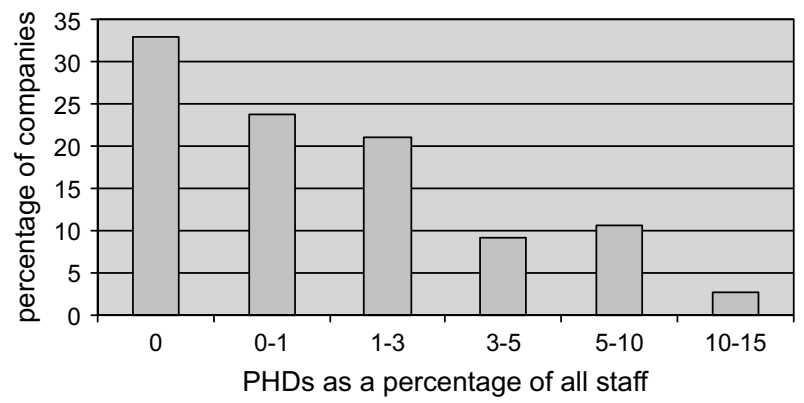

Figure 6. Ph.Ds in process R\&D as a percentage of all staff. 


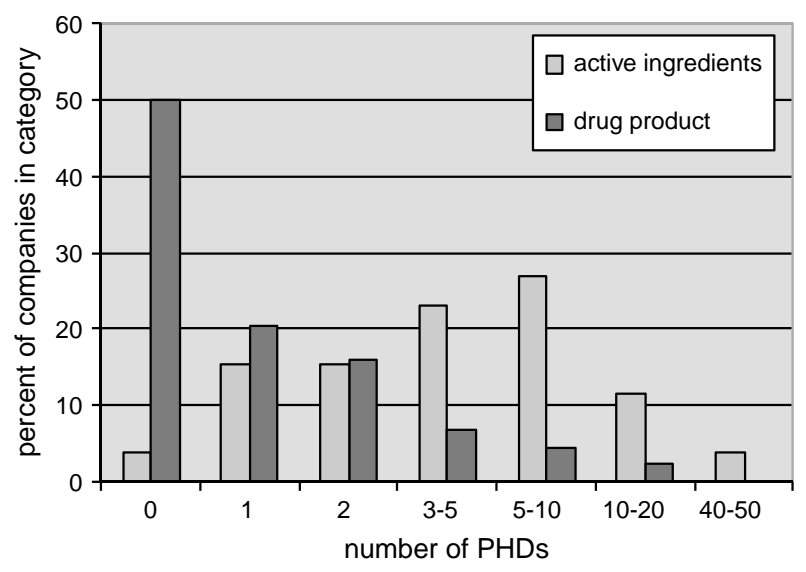

Figure 7. Number of $\mathrm{PhDs}$ in process $\mathrm{R} \& \mathrm{D}$ by sub-sector.

the active ingredient sub-sector these stages tend to involve staff with a higher level of education.

\section{Evolution of process $R \& D$}

It has been shown that the number of people involved in process $R \& D$ has grown in a substantial number of establishments and that employment in process R\&D has grown faster than total employment in the pharmaceutical companies. This section investigates the evolution of the process $\mathrm{R} \& \mathrm{D}$ activities in terms of the actual scope of the activities and the role of Irish establishments.

The interviews confirmed that the greater role of Irish subsidiaries in process $\mathrm{R} \& \mathrm{D}$ was primarily driven by a desire on the part of the pharmaceutical companies to increase the efficiency and speed of process R\&D activities in the face of global changes in the competitive and technological environment since the 1980 (see also Van Egeraat and Breathnach 2008). Under pressure to increase efficiency in R\&D, pharmaceutical companies have located process $R \& D$ activities near branch plants to facilitate integration of, and communication between, the process R\&D function and the manufacturing operations. In most of the Irish subsidiaries the greater role did not develop overnight, however. The interviews showed that, although some, more recently established, operations have been involved in a relatively broad range of process $R \& D$ activities from the start of operations, the evolution of the role of most establishments is characterised by incremental upgrading.

Most plants had a very limited role in process R\&D at the time of establishment. Typically, involvement in process $R \& D$ originated from a manufacturing support or technical services unit such as can be found in most pharmaceutical plants. Over time these units increased their involvement in a range of process $R \& D$ activities, notably continuous improvement, and technology-transfer-related activities such as running of validation batches and optimisation. This was usually a gradual process which typically led to the formation of a separate group within technical services or the establishment of a separate process development unit. 'It gets to a state where you give it a name' (Manager Process Technology Unit, formulation plant, firm 8, 2006). 
In some cases such upgrading was followed by the establishment of a pilot plant, which would typically have had multiple functions. It would have served as a troubleshooting facility to facilitate the continuous improvement and optimisation activities, and as a production unit for clinical trials. These developments, in turn, have in some cases led to an earlier and more substantial involvement of local staff in the up-stream stages of the process $R \& D$ cycle. Local establishments that have reached this level of involvement and mandate are typically considered as one of the few 'strategic sites' in the global network of the company, with responsibility for new product launches. In a very small number of cases such developments have been followed by the establishment of units involved in activities at an even earlier stage of the process $R \& D$ cycle, such as pre-formulation research units, or units with a greater geographical mandate (for example facilities to develop second-generation processes for the global network). Such units are typically part of the global R\&D organisation of the company.

\section{A case study of the evolution of process $R \& D$ activities}

This sub-section presents a case study of how the process R\&D function has evolved in one pharmaceutical company based in Ireland. The firm in question is a subsidiary of a global UK/US-based pharmaceutical company, formed from a recent merger. In the rationalisation process that followed the merger, the number of manufacturing sites was reduced from 108 to 80 . The company now operates 13 active ingredient plants in a range of countries, two of which (those in Ireland and Singapore) are considered 'strategic', i.e. responsible for the introduction of new product out of the R\&D pipeline and the global supply of key substances to the drug product plants. Each of these two plants is responsible for about one-third of the company's active ingredients output. R\&D is conducted in over 20 sites worldwide. The number of sites and their locations are partly a legacy of the strong merger and acquisition history of the company. Chemical process R\&D is strongly concentrated at two main locations in the UK and the USA. One of these chemical R\&D groups (UK) employs about 250 staff. Some decentralisation occurred in the 2000s with the establishment of two new pilot plants at the strategic substance manufacturing sites, firstly in Ireland and later in Singapore.

The Irish subsidiary was established in the mid-1970s as a drug substance manufacturing plant. For a long time the plant was responsible for the production of one of the main blockbuster products of the company. Production was supported by a typical technical support team of eight people. During the 1990s, this group steadily increased its process-development-related activities. In the early 1990s it began to work on process optimisation. From 1994 on, more and more new products started to be introduced in the plant and the facility was designated as the principal strategic site for drug substance manufacturing in the company's network. To facilitate this, the technical support team increased its involvement in technology transfer and the running of validation batches. By the end of the 1990s, the team had grown to 20 staff.

In the second half of the 1990s, the UK-based chemical development (R\&D) division, in partnership with the manufacturing organisation, decided to establish a pilot plant at the Irish manufacturing site. This came on-stream in 2001. The pilot 
plant is used for the manufacture of clinical trial material and for the development of chemical processes. The first of these functions is carried out by locally-based operators from the chemical development organisation. The second function is carried out by teams made up of staff from the synthetic chemistry organisation and the now-renamed 'technical operations' group. Although the pilot plant is located in Ireland, many of the staff of the chemical development organisation working on pilot development are actually based in the UK/USA. Each time they decide to put a new product into the Irish pilot plant, UK/USA-based staff come over to Ireland to conduct work on the process in conjunction with local chemists and engineers seconded from the technical operations group. Due to seamless links with the central development groups, including remote tuning of research equipment, elements of the development work and data analysis in the pilot plants can actually be conducted from the UK/USA. Although it is a team effort, much of the actual development work is in the hands of the UK staff. Typically staff from the local technical operations group take a very active involvement towards the end of Phase III when a technology transfer team is put in place to move the process into the commercial manufacturing plant. The pilot plant was further expanded in 2004 and now employs 25 staff, made up of 12 technical staff and 13 operators.

At the beginning of the $2000 \mathrm{~s}$, the technical operations group increased its involvement in process redevelopment of the drug substance (second generation). Redevelopment is again a team effort involving the manufacturing and R\&D organisations. However the second-generation project is 'owned' by the technical operations group in the manufacturing organisation. This group also carries out most of the development work. This work required an expansion of the local skills set, notably in the area of physical properties of the drug substance, synthetic chemistry and engineering scale-up. In 2004 a new physical properties laboratory was established to accommodate the 10 additional researchers.

In 2004 the role of the Irish subsidiary was further expanded with the establishment of a pre-formulation facility for drug products, employing a further 10 staff. The activities are as much related to drug product development as they are to active ingredient development (and both types of sites were considered as a location). But due to the specific technology involved, it was deemed to be more appropriate to have this particular part of the formulation development on an active ingredient site.

So, over a period of 15 years, the process R\&D activities of the Irish facilities have been significantly enhanced. From a situation where there was no involvement in process R\&D at the start of the 1990s, by 2005 the Irish subsidiary had a core development group of about 40 people (not including about 10 operators in the pilot plant and a further 10 staff for technical support of the commercial plant) involved in various aspects of the process $R \& D$ cycle. The qualifications of the staff suggest a high level of value creation - 38 of the 40 staff in the core group have a $\mathrm{PhD}$ degree.

Yet, even in this success story, the involvement of the Irish staff mainly concerns the final phases of the process R\&D cycle. The early stage active ingredient process research and process development work for new substances is in the hands of staff based at the central active ingredient R\&D sites in the UK and USA. 


\section{Conclusions}

For a long time the pharmaceutical industry in Ireland exhibited a strongly truncated character, dominated by foreign branch plants focussing on production with little control or R\&D functions. The Irish government has specifically identified process R\&D as an opportunity for higher value-added activities in the industry. This has been inspired by evidence that transnational pharmaceutical companies are changing the organisation of their internal process R\&D activities. Since the 1980s, confronted with changes in the global competitive and technological environment, pharmaceutical companies have come under pressure to increase the efficiency in process R\&D. Part of the answer is sought in a greater co-ordination between the various R\&D activities as well as between $\mathrm{R} \& \mathrm{D}$ and other functions, including manufacturing and sales.

The principal objective of this article has been to analyse how these organisational developments affect the relative strength of spatial concentration and deconcentration forces impacting on the process $R \& D$ functions and to describe how this is reflected in the changing nature of process $R \& D$ activities of pharmaceutical enterprises operating in Ireland. To achieve this objective, this article has opened the 'black box' of process R\&D in pharmaceutical companies. It has shown that, far from being a uniform, undifferentiated function, process R\&D in the pharmaceutical industry comprises a wide range of activities that individually involve different tendencies in relation to decentralisation.

The survey data show that process $R \& D$ activities in Ireland have expanded rapidly with process $R \& D$ staff numbers growing at a substantially faster rate than overall employment numbers in the industry. In addition, more than half of the surveyed companies reported that they had concrete plans to expand their process $\mathrm{R} \& \mathrm{D}$ activities in Ireland over the following five years. However, the number of people employed in process $R \& D$ varies considerably from company to company. In addition, staff involved in process $\mathrm{R} \& \mathrm{D}$ are not necessarily working in dedicated process $\mathrm{R} \& \mathrm{D}$ units but are often part of other functions, notably production, technical support and quality control.

The interviews show that most of the longer-established subsidiaries of transnational companies have experienced an incremental upgrading process over time. The interviews support the idea that the changes in the global competitive and technological environment, and the resulting search for efficiency in process R\&D cycle, have been the primary driver for the decentralisation of process R\&D activities to Ireland.

By unpacking the 'black box' of process R\&D, the study has been able to show that this has been a selective decentralisation process, involving specific stages only. Although Irish subsidiary staff, as members of global project teams, have at least some involvement in most process R\&D activities, this involvement only becomes substantial after the proof-of-concept point of the cycle, at the start of the Phase III clinical trials. This is the point at which companies generally want to have locked down the process parameters. From here on, process R\&D activities focus on the final details of the process and technology transfer.

Part of the explanation lies in the contrasting spatial configuration of the two functions that process $R \& D$ needs to liaise with: product $R \& D$ and manufacturing. As discussed, firms increasingly tend to concentrate their high-level and 
innovative research at laboratories located in the core global 'megacentres' for innovation. On the other hand, pharmaceutical companies are operating relatively decentralised manufacturing networks with plants located in many countries. In this situation, decentralisation of process $R \& D$ to the branch plants may facilitate knowledge exchange with manufacturing, but it will decrease the efficiency of knowledge flow between staff involved in process R\&D and staff involved in product R\&D located in the core regions (see also Malecki 1997). For the early stages in the process R\&D cycle the efficiency of knowledge exchange with the product $R \& D$ function weighs more strongly than the link with the manufacturing function.

The fact that the subsidiaries of pharmaceutical companies in Ireland tend to focus on the last stages of the process $R \& D$ cycle does not necessarily discount the sophistication of the process R\&D activities in Ireland - nearly all staff involved in process R\&D hold a third-level degree and 30\% hold a PhD. Yet there are important differences between sub-sectors. Although there are no systematic differences between local active ingredient and drug formulation plants with respect to the level of involvement of staff in the various process $R \& D$ activities, active ingredient plants tend to involve staff with a higher level of education.

The findings highlight opportunities and challenges for Ireland in its pursuit of process R\&D functions and jobs in the pharmaceutical industry. On the one hand there is great opportunity for expansion of activities in the final stages of the process R\&D cycle, either through the establishment of new process R\&D units or in the form of expansion of staff numbers at existing units. In itself, this requires further efforts to expand and upgrade the national pool of workers with relevant process development skills.

On the other hand serious challenges remain in relation to the up-stream phases of the process $\mathrm{R} \& \mathrm{D}$ cycle. In the short term the Irish government's latitude to stimulate these up-stream phases is limited. Corporations will prove very reluctant to move such activities away from their core product $R \& D$ units and it is questionable whether such up-stream process $R \& D$ activities can be developed in Ireland without the parallel development of a product R\&D infrastructure. The product $\mathrm{R} \& \mathrm{D}$ functions of transnational companies are becoming increasingly concentrated in a small number of global innovation 'megacentres' and, as yet, none of the Irish regions comes close to joining this league (Van Egeraat et al. 2009).

This is for a large part a reflection of Ireland being an 'industrial latecomer' (O’Malley 1989) with an industrial development model that for a long time was focussed on inward foreign direct investment (Van Egeraat and Breathnach 2007). Establishing Ireland as an innovation arena will require at least a greater focus on the development of indigenous innovation capacity, both in the form of university departments, research institutes and (start-up) indigenous companies. The Strategy for Science Technology and Innovation (DETE 2006) and the more recent 'Smart Economy' document launched by the Irish Government (Government of Ireland 2008) include many elements that will support such a development. But, even if fully implemented, it will be many years before this strategy bears fruit and Ireland achieves a strategic concentration of product $\mathrm{R} \& \mathrm{D}$ in the pharmaceutical industry. 


\section{Acknowledgements}

The research for this paper was partly supported by a grant from the Irish Research Council for the Humanities and Social Sciences and would not have been possible without the support of staff at IDA Ireland, notably Barry O'Leary and Pat McGovern. In addition I would like to thank Proinnsias Breathnach, Declan Curran and the anonymous referees for their constructive comments.

\section{References}

Amin, A., 1994. Post-Fordism: models, fantasies and phantoms of transition. In: A. Amin, ed. Post-Fordism: a reader. Oxford: Blackwell, 1-37.

Britton, J. and Gilmour, J., 1978. The weakest link: a technical perspective on Canadian industrial underdevelopment. Background Study 43. Ottawa: Science Council of Canada.

Chesbrough, H., 2003. Open Innovation: the new imperative for creating and profiting from technology. Boston, MA: Harvard Business School Press.

Chiesa, V., 1996. Separating research from development: evidence from the pharmaceutical industry. European Management Journal, 14 (6), 638-647.

Childs, P., 1996. The chemical industry in Cork. Chemistry in Action, 47, 1-7.

Collins, P. and Grimes, S., 2008. Ireland's foreign-owned technology sector: evolving towards sustainability? Growth and Change, 39 (3), 436-463.

Cooke, P., 2004. The molecular biology revolution and the rise of bioscience megacentres in North America and Europe. Environment \& Planning C: Government \& Policy, 22 (2), 161177.

Cooke, P., 2005. Rational drug design, the knowledge value chain and bioscience megacentres. Cambridge Journal of Economics, 29 (3), 325-341.

Cooke, P., 2007. Growth cultures: the global bioeconomy and its bioregions. London: Routledge.

DETE, 2006. Strategy for science technology and innovation, 2006-2013. Dublin: Department of Enterprise, Trade and Employment.

Dicken, P., 2003. Global shift: reshaping the global economic map in the $21^{\text {st }}$ century. London: Thousand Oaks.

Dicken, P., 2007. Global shift: mapping the changing contours of the World economy. London: Sage.

Egeraat, C. van, 2006. Spatial concentration in the Irish pharmaceutical industry: the role of government intervention and agglomeration economies, NIRSA Working Paper 28. Maynooth: National Institute for Regional and Spatial Analysis, National University of Ireland Maynooth.

Egeraat, C. van, 2007. The scale and scope of process R\&D in the Irish pharmaceutical industry, NIRSA Working Paper 32. Maynooth: National Institute for Regional and Spatial Analysis, National University of Ireland Maynooth.

Egeraat, C. van and Barry, F., 2009. The Irish pharmaceutical industry over the boom period and beyond. Irish Geography, 42 (1), 23-44.

Egeraat, C. van and Breathnach, P., 2007. The manufacturing sector. In: B. Bartley and R. Kitchin, eds. Understanding contemporary Ireland. London: Pluto Press.

Egeraat, C. van and Breathnach, P., 2008. The drivers of transnational subsidiary evolution: the upgrading of process R\&D in the Irish pharmaceutical industry, NIRSA Working Paper 38. Maynooth: National Institute for Regional and Spatial Analysis, National University of Ireland Maynooth.

Egeraat, C. van, O'Riain, S. and Kerr, A. 2009. Social and spatial structures of collaboration and innovation in the knowledge economy. Deliverable 11.2 for EU FP6 OPAALS Research Project. Available from: http://wiki.opaals.org/DeliverableAbstracts.

Enterprise Strategy Group, 2004. Ahead of the curve. Dublin: Farfas.

Government of Ireland, 2008. Building Ireland's smart economy: a framework for sustainable economic renewal. Dublin: The Stationery Office.

Hayter, R., 1998. Research and development. In: P. Daniels and W. Lever, eds. The global economy in transition. Harlow: Longman, 64-190.

Howells, J., 1983. Filter-down theory: location and technology in the UK pharmaceutical industry. Environment and Planning A, 15 (2), 147-164. 
Howells, J., 1984. The location of research and development: some observations and evidence from Britain. Regional Studies, 18 (1), 13-29.

Howells, J., 1990. The internationalisation of R\&D and the development of global research networks. Regional Studies, 24 (6), 495-512.

Howells, J., 1995. Going global: the use of ICT networks in research and development. Research Policy, 24 (2), 169-184.

ICSTI (Irish Council for Science Technology and Innovation), 2003. Embedding the pharmachem industry in Ireland. Dublin: ICSTI.

Industrial Policy Review Group, 1992. A Time for change: industrial policy for the 1990s. Dublin: Stationery Office.

Malecki, E., 1997. Technology \& economic development: the dynamics of local, regional and National competitiveness. Harlow: Addison Wesley Longman.

O'Malley, E., 1989. Industry and economic development: the challenge for the latecomer. Dublin: Gill and Macmillan.

Pisano, G., 1997. The development factory: unlocking the potential of process innovation. Boston, MA: Harvard Business School Press.

Watts, H., 1981. The branch plant economy. Harlow: Longman.

White, P., 2000. The muscles of the Celtic Tiger: IDA's winning sectors. In: R. MacSharry and P. White, eds. The making of the Celtic Tiger. Cork: Mercier Press, 272-308.

Zeller, C., 2004a. Project teams as means of restructuring research and development in the pharmaceutical industry. Regional Studies, 36 (3), 275-289.

Zeller, C., 2004b. North Atlantic innovative relations of Swiss pharmaceuticals and the proximities with regional biotech arenas of restructuring research and development in the pharmaceutical industry. Economic Geography, 80 (1), 83-111. 